\title{
Rice genome sequencers cook up merger
}

\section{Declan Butler}

The two public groups and two private companies sequencing the rice genome are discussing ways to merge their efforts into a single joint project.

Researchers believe that such cooperation would greatly accelerate the completion of the genome. Draft maps for two subspecies of rice (Oryza sativa) were published on 5 April - Swiss-based agricultural biotechnology company Syngenta covered japonica (S. A. Goffet al. Science 296, 92-100; 2002), and the publicly funded Beijing Genomics Institute sequenced indica (J. Yu et al. Science 296, 79-92;2002).

Representatives of these groups, together with those from biotechnology firm Monsanto of St Louis, Missouri, and from the other public project, the Japanese-led International Rice Genome Sequencing Project (IRGSP), could meet within weeks to organize the merger. If they reach agreement, an announcement of the deal could take place at next month's IRGSP workshop in France.

The move follows complaints from some researchers about access to sequence data for Syngenta's draft map of japonica (see Nature 416, 111-112; 2002). Syngenta makes the data available to academic researchers for non-commercial purposes at its own website, rather than depositing the information in GenBank.

But access is governed by a number of conditions. Researchers can only search up

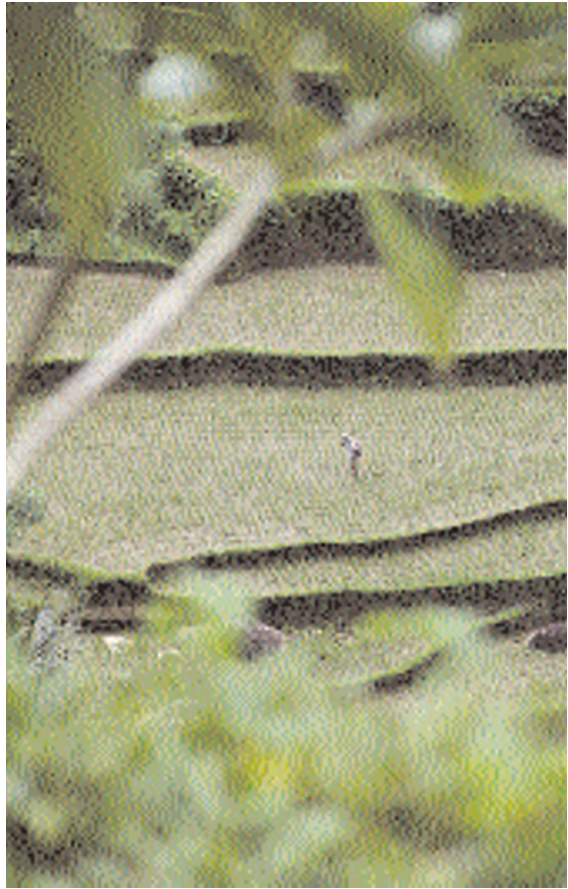

Steaming ahead: cooperation would speed up the completion of the rice genome sequence.

to 15,000 base pairs of the sequence at a time, and download only 100,000 base pairs of sequence each week. More can be freely downloaded if the researchers' institutions sign an agreement with Syngenta stating that the data will not be used for commercial ends.
But Syngenta last week announced that it will make its data available to the IRGSP, effectively ensuring that they end up in GenBank, mingled with the IRGSP's results. Syngenta completed its draft sequence last year but, despite providing the IRGSP with mapping data, it had until now refused to share raw sequence data with all members of the public project - unlike its rival Monsanto, whose contributions of sequence data are credited with accelerating the IRGSP's effort.

The merger idea came in a written proposal to the IRGSP from Stephen Goff, head of Syngenta's Torrey Mesa Research Institute in San Diego, California, and Jun $\mathrm{Yu}$, associate director of the Beijing Genomics Institute.

The proposal would mirror the cooperation between Celera, the Maryland-based genome-sequencing company, and the public project headed by Gerry Rubin at the University of California, Berkeley, on the fruitfly Drosophila. That deal sped up assembly of the genome and improved data quality (see Nature 401, 729-730; 1999).

Cooperation on rice could result in the genome being completed next year - two years ahead of the current schedule, participants in the discussions say. The collaboration might also extend to annotating the raw sequence with information such as the identity of genes and their function in rice.

portal.tmri.org/rice

\section{Government warned over future of cash-starved labs}

\section{David Adam, London}

Out of date, out of shape and in need of heavy investment, the laboratories of Britain's universities have joined its railways and health service as a cause of national lament after a damning report found they urgently need a $\mathfrak{E 3 - b i l l i o n}$ (US\$4.3-billion) fix.

The report, issued on 25 March, was commissioned by the Office of Science and Technology (OST) from consultancy firm JM Consulting. It says the lack of investment in buildings, support staff and equipment could threaten Britain's scientific future.

"Without this investment there will remain a serious problem, which is causing significant stress to institutions, and actual damage to the present and future research output," the report warns. "There is the expectation of more serious and destabilising effects if current trends continue." The OST will use the report, Study of Science Research Infrastructure, to try to squeeze more money out of the forthcoming governmental spending review.
The study says that recent government initiatives such as the Joint Infrastructure Fund (JIF) and the Science Research Infrastructure Fund (SRIF) - which offered universities $\mathfrak{E} 2$ billion to improve facilities - have had little impact. Only $15 \%$ of labs got any money, as most of it was went into construction projects with tangible research benefits, rather than general maintenance.

"We now have a new building with capacity for $\mathbf{4 5 0}$ scientists but no money for a porter or a receptionist," said an official at one of the 20 unnamed institutions contacted during the survey.

JIF required universities to match any funds provided, and many institutions did this by draining the cash from other projects.

“The ability to 'make do' has been a powerful factor to the benefit of UK science," the report says. However, a new generation of researchers is less tolerant of "working long hours in poor environments with inefficient equipment", it says.

But lobbyists are reluctant to attack a government that has improved science funding in recent years. "It is not realistic to expect years of underinvestment to be reversed overnight," says Richard Joyner, chairman of pressure group Save British Science. "JIF and SRIF were just the first attempt to sort out a very difficult problem."

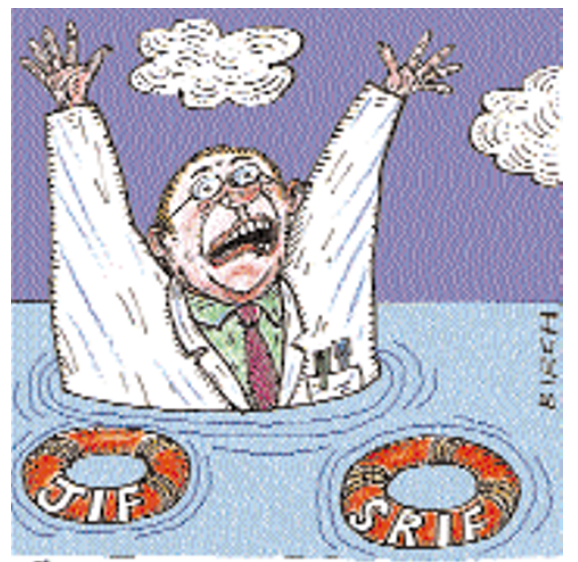

STILL GOINGT VNDER.. 